\title{
Systemic Induction and Role of Mitochondrial Alternative Oxidase and Nitric Oxide in a Compatible Tomato-Tobacco mosaic virus Interaction
}

\author{
Li-Jun Fu, ${ }^{1}$ Kai Shi, ${ }^{1}$ Min Gu, ${ }^{1}$ Yan-Hong Zhou, ${ }^{1}$ De-Kun Dong, ${ }^{3}$ Wu-Sheng Liang, ${ }^{4}$ Feng-Ming Song, \\ and Jing-Quan $\mathrm{Yu}^{1,2}$ \\ ${ }^{1}$ Department of Horticulture, Huajiachi Campus, Zhejiang University, ${ }^{2}$ Key Laboratory of Horticultural Plants Growth, \\ Development and Quality Improvement, Agricultural Ministry of China, ${ }^{3}$ The Institute of Crop and Nuclear Technology \\ Utilization, Zhejiang Academy of Agricultural Sciences, and ${ }^{4}$ Department of Plant Protection, Institute of Biotechnology, \\ Huajiachi Campus, Zhejiang University, Kaixuan Road 268, Hangzhou, P.R. China
}

Submitted 27 February 2009. Accepted 19 June 2009.

The role of mitochondrial alternative oxidase (AOX) and the relationship between AOX and nitric oxide (NO) in virusinduced systemic defense to Tobacco mosaic virus (TMV) were investigated in susceptible tomato (Solanum lycopersicum) plants. TMV inoculation to the lower leaves induced a rapid NO synthesis and AOX activation in upper uninoculated leaves as early as 0.5 day postinoculation. Application of exogenous potassium cyanide (KCN, a cytochrome pathway inhibitor) at nonlethal concentrations and NO donor diethylamine NONOate (DEA/NO) to the upper uninoculated leaves greatly induced accumulation of AOX transcript, reduced TMV viral RNA accumulation, and increased the leaf photochemical quantum yield at photosystem II. Pretreatment with NO scavenger almost completely blocked TMV-induced AOX induction and substantially increased TMV susceptibility. Salicylhydroxamic acid (SHAM, an AOX inhibitor) pretreatment reduced the DEA/NO-induced cyanide-resistant respiration and partially compromised induced resistance to TMV. Conversely, KCN and SHAM pretreatment had very little effect on generation of NO, and pretreatment with NO scavenger did not affect $\mathrm{KCN}$-induced $\mathrm{AOX}$ induction and TMV resistance. These results suggest that TMV-induced NO generation acts upstream and mediates AOX induction which, in turn, induces mitochondrial alternative electron transport and triggers systemic basal defense against the viral pathogen.

Mitochondrial respiration provides energy necessary to drive metabolic and transport processes in cells. Plant mitochondria possess two different pathways of electron transport at the ubiquinone level: the cytochrome pathway (Cyt pathway) terminated at cytochrome $c$ oxidase (COX) and the cyanide (CN)-resistant alternative pathway which involves only a single quinol oxidase termed the alternative oxidase (AOX) (Siedow and Umbach 1995; Arnholdt-Schmitt et al. 2006). Electron transfer through the Cyt pathway is coupled to the generation of an electrochemical gradient used to produce ATP. However, electron flow from ubiquinone to AOX is not coupled to ATP production. The function or functions of this nonphosphorylating path in nonthermogenic respiratory metabolism is not well defined (Purvis and Shewfelt 1993;

Corresponding author: Kai Shi; Telephone: 0086-57186971120; Fax: 00 86-57186049815; E-mail: kaishi@zju.edu.cn
Amirsadeghi et al. 2007; Vidal et al. 2007). Although AOX protein level and $\mathrm{CN}$-resistant respiration are low in unstressed plants, they were all enhanced after exposure to pathogens, low temperature, hypoxia, high light intensity, and other stresses (Szal et al. 2003; Yoshida et al. 2007; Király et al. 2008; Watanabe et al. 2008). Therefore, the CN-resistant alternative pathway may play an important role in stress tolerance. It has also been suggested that enhanced operation of the alternative pathway plays a role in protecting plant cells from the attack of reactive oxygen species (ROS) (Maxwell et al. 1999; Umbach et al. 2005) and in the maintenance of plant homeostasis in response to biotic and abiotic stresses (Moore et al. 2002).

Plant mitochondria are implicated in both local and systemic defenses against pathogen infection. In Arabidopsis, induction of AOX in leaves infiltrated with both avirulent and virulent Pseudomonas syringae pv. tomato DC 3000 are accompanied with local necrosis, while increased respiration appears to be associated with symptom development rather than resistance response (Simons et al. 1999). Treatment with a proteinaceous bacterial elicitor, harpin, also resulted in an increased expression of the AOXla gene in Arabidopsis suspension cells, and the induction of AOX was suggested to be a protecting or scavenging system (Krause and Durner 2004). Nevertheless, the significance of the alternative respiratory pathway during pathogen attack still remains to be elucidated.

Unlike some fungi and eubacteria, viruses, which do not have AOX protein (Vanlerberghe and McIntosh 1997; AvilaAdame and Köller 2002), provide good pathogen systems for investigating the role of cyanide-resistant respiration in the plant defense response. AOX is often induced during plantvirus interactions (Lennon et al. 1997; Chivasa and Carr 1998). In directly inoculated tissue, several lines of evidence have supported the idea that the AOX-dependent signal transduction pathway plays roles in mediating virus localization and limiting host tissue necrosis (Chivasa and Carr 1998; Dutilleul et al. 2003; Love et al. 2005; Király et al. 2008). However, the role of AOX in plant systemic basal defense against viral pathogens remains elusive. NPRl is a key regulator of systemic defense responses in both compatible or incompatible plant interactions with bacterial and fungal pathogens (Chivasa and Carr 1998; Wong et al. 2002) but not with viral pathogens. Tobacco resistance to Tobacco mosaic virus (TMV), Potato virus $X$ (PVX), and Cucumber mosaic virus (CMV) can be stimulated by inhibitors of the Cyt path- 
way (e.g., antimycin A and potassium cyanide [KCN]) but the resistance is not associated with NPR1-regulated $P R-1$ expression. Similarly, virus replication and systemic movement in tobacco were antagonized by the AOX inhibitor salicylhydroxamic acid (SHAM) (Chivasa et al. 1997; Naylor et al. 1998; Mayers et al. 2005). In Arabidopsis thaliana, resistance to Turnip vein clearing virus (TVCV) can be induced by cyanide and antimycin A in nprl mutants (Kachroo et al. 2000; Wong et al. 2002). These observations suggest that AOX may play a crucial role in the induction of systemic basal defense to viruses through a signaling pathway distinct from those against bacterial and fungal pathogens (Murphy et al. 1999; Wong et al. 2002; Singh et al. 2004). However, results from these experiments should be interpreted with caution because these results are mainly obtained with tobacco and Arabidopsis, and some of these experiments were carried out using detached leaves (Chivasa et al. 1997; Chivasa and Carr 1998). In squash (Cucurbita pepo), neither antimycin A or $\mathrm{KCN}$ induced resistance to $\mathrm{CMV}$, and $\mathrm{AOX}$ inhibitors that compromise salicylic acid (SA)-induced resistance to CMV in tobacco did not inhibit SA-induced resistance to the virus in squash (Mayers et al. 2005). In Phaseolus vulgaris, $A O X$ genes showed low constitutive expression after infection by White clover mosaic virus (WClMV) (Gális et al. 2004). To date, it is not clear whether AOXs in upper uninoculated leaves play roles in systemic basal defense in compatible plant-virus interactions.

In recent years, nitric oxide (NO) has been demonstrated to be an important signaling molecule that regulates plant development and responses to environmental cues, including pathogen infection (Floryszak-Wieczorek et al. 2007; Asai et al. 2008; Tada et al. 2008). Huang and associates (2002) demonstrated the NO-induced transcriptional activation of AOX and the CN-resistant respiration in Arabidopsis suspension cells. Inversely, several lines of evidence have indicated that mitochondria may be one of the main sites of NO synthesis (Salgado et al. 2006). Mitochondrial electron transport was found to be involved in NO emission from tobacco leaves and cell suspensions (Planchet et al. 2005). These studies indicate that NO generation may be connected with AOX induction in plants. However, the interrelationship between mitochondrial AOX induction and NO generation as well as their roles in plant antiviral response remains to be determined.
Like other important crop plants, tomato can be infected by a large number of virulent viral pathogens. In the present study, using pharmacological and biochemical approaches, we have investigated the role of AOX and the relationship between AOX and NO in compatible interactions between tomato and TMV (U1 strain). TMV-induced AOX induction is enhanced by NO and reversed by NO synthesis inhibition, whereas KCN and SHAM have no significant effect on TMVinduced NO evolution. Our results show that NO is required for TMV-induced AOX induction which, in turn, induces mitochondrial alternative electron transport and promotes systemic basal defense against TMV.

\section{RESULTS}

\section{Systemic induction of $\mathrm{NO}$ accumulation and $\mathrm{CN}$-resistant respiration by TMV infection.}

$\mathrm{CN}$-resistant respiration and NO accumulation were determined in the compatible interactions between TMV and tomato plants (Figs. 1 and 2). In upper uninoculated leaves, CNresistant respiration started to increase from 0.5 day postinoculation (dpi) and reached a maximum at $1 \mathrm{dpi}$. Meanwhile, there was significant increase in total respiration from 1 to 7 dpi (Fig. 1A). The relative transcript abundance of $A O X$ genes at 4 dpi was analyzed by real-time reverse-transcription polymerase chain reaction (RT-PCR) (Fig. 1B). TMV inoculation led to 7.1-, 2.9-, and 2.6-fold increases in expression of $A O X 1 a, A O X 1 b$, and $A O X 1 c$, respectively, but had little effect on the $A O X 2$ transcript. Therefore, the AOX1a, AOX1b, and $A O X 1 c$ genes were selected for further study.

Concomitant with the induction of $\mathrm{CN}$-resistant respiration, NO generation was increased in upper uninoculated leaves by 3.5-fold at 0.5 dpi (Fig. 2) and there was less increase afterward. In TMV-inoculated plants, NO content was $50.8 \%$ higher than that in mock-inoculated plants at $10 \mathrm{dpi}$.

\section{TMV-induced AOX induction is enhanced by NO and reversed by NO synthesis inhibition but KCN and SHAM did not influence TMV-induced NO evolution.}

To investigate the possible involvement of mitochondrial AOX and NO in response to TMV inoculation, we first analyzed TMV-induced CN-resistant respiration and AOX tran-
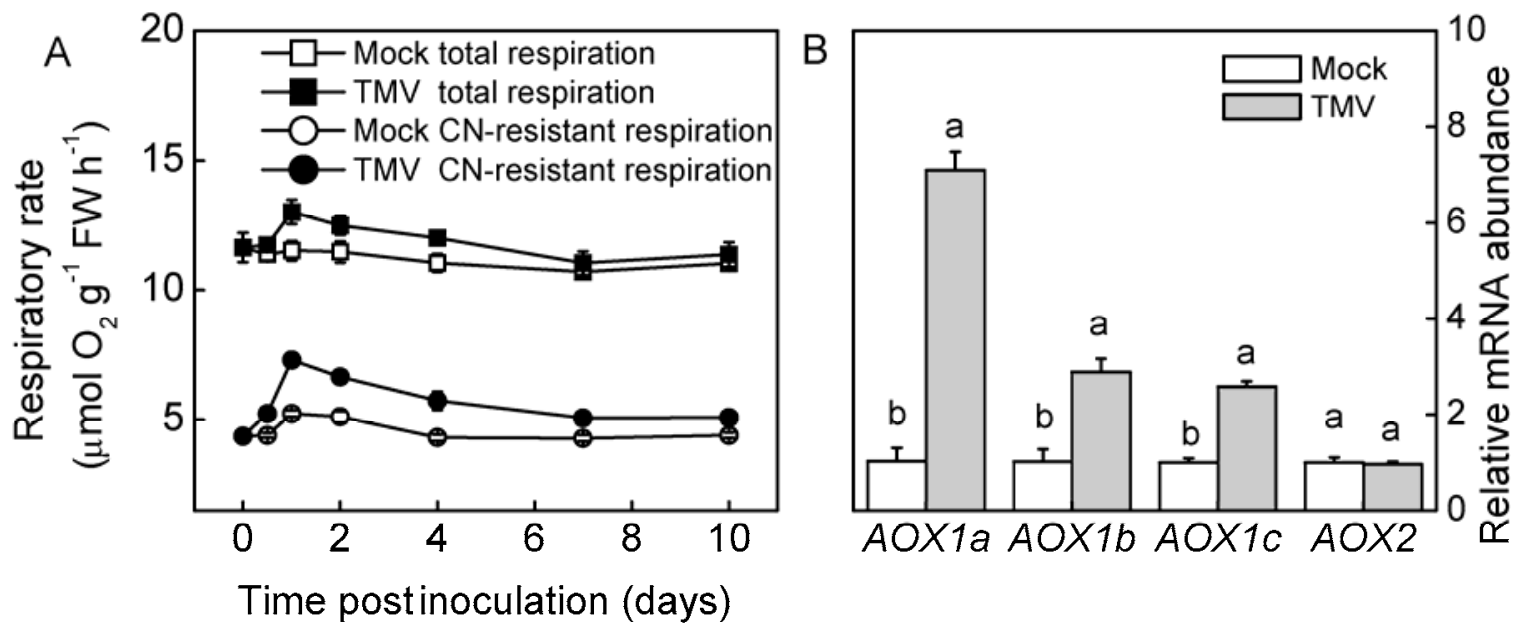

Fig. 1. Changes in leaf respiratory rate and transcript level of alternative oxidase (AOX) genes in upper uninoculated leaves of tomato plants postinoculation with Tobacco mosaic virus (TMV) on a lower leaf. A, Time-course changes in the leaf total respiration rate and cyanide (CN)-resistant respiration rate. Squares, total respiration; circles, CN-resistant respiration. Open symbols indicate mock plants and closed symbols indicate TMV-inoculated plants. B, Transcript level of AOX genes in mock-inoculated (while bars) and TMV-inoculated (gray bars) plants were measured by quantitative real-time polymerase chain reaction. Leaf samples were collected 4 days postinoculation. Values are given after normalization with Actin and compared with the mock-inoculated plants (set at 1$)$. Results are mean values \pm standard deviation; $n=4$. Different letters depict significant differences between the treatments $(P<0.05)$. 
scripts as affected by exogenous NO (Fig. 3). Pretreatment with diethylamine NONOate (DEA/NO), a NO chemical donor, increased $\mathrm{TMV}$-induced $\mathrm{CN}$-resistant respiration and $A O X 1 a, A O X 1 b$, and $A O X 1 c$ transcripts by $24.2,9.8,56.3$, and $109.5 \%$, respectively, over those in the unpretreated plants. In contrast, treatment with 2-(4-carboxyphenyl)4,4,5,5-tetramethylimidazoline-1-oxyl-3-oxide (cPTIO, a specific NO scavenger) completely blocked the induction of $\mathrm{CN}$-resistant respiration and AOX transcripts. As expected, the $\mathrm{TMV}$-induced increase in $\mathrm{CN}$-resistant respiration and transcripts of $A O X 1 a, A O X 1 b$, and $A O X 1 c$ genes were further enhanced by KCN (a Cyt pathway inhibitor) but reduced by SHAM (an AOX inhibitor). However, TMV-induced $\mathrm{CN}$ resistant respiration was increased by $18.7 \%$ in $\mathrm{KCN}+$ cPTIO+TMV treatment but decreased by $42.3 \%$ in DEA/ $\mathrm{NO}+\mathrm{SHAM}+\mathrm{TMV}$ treatment over that of the unpretreated plant. Interestingly, the $A O X 1 b$ transcript level was significantly increased for both treatments.

Because TMV-induced AOX induction is enhanced by NO but blocked by NO elimination, we determined whether TMVinduced NO synthesis is affected by mitochondrial electron transport (Fig. 4). The confocal laser scanning microscope (CLSM) method was used to detect the changes in NO in leaves. There was an increase in green fluorescence signal in TMV-inoculated plants when compared with that of mockinoculated plants (Fig. 4A and B). Because the green fluorescence detected with CLSM disappeared after addition of 100 $\mu \mathrm{M}$ cPTIO, the visual signal could be ascribed to NO accumulation. Pretreatments with either KCN or SHAM had no significant effect on TMV-induced NO production (Fig. 4C and D), suggesting that mitochondrial electron transport was not required for NO synthesis. Application of NO donor in either DEA/NO+TMV or DEA/NO+SHAM+TMV treatments resulted in a significant increase of fluorescence over TMV treatment, and the increases were substantially reduced by the pretreatment with the NO scavenging compounds (Fig. 4E to $\mathrm{H}$ ). Similar effects of KCN and SHAM on leaf NO accumulation were observed when an independent Greiss reagent method was used for detection of NO (Fig. 4I).

Taken together, TMV-induced AOX induction in uninoculated tomato leaves is NO-sensitive while TMV-induced NO evolution is not affected by $\mathrm{KCN}$ or SHAM. These results

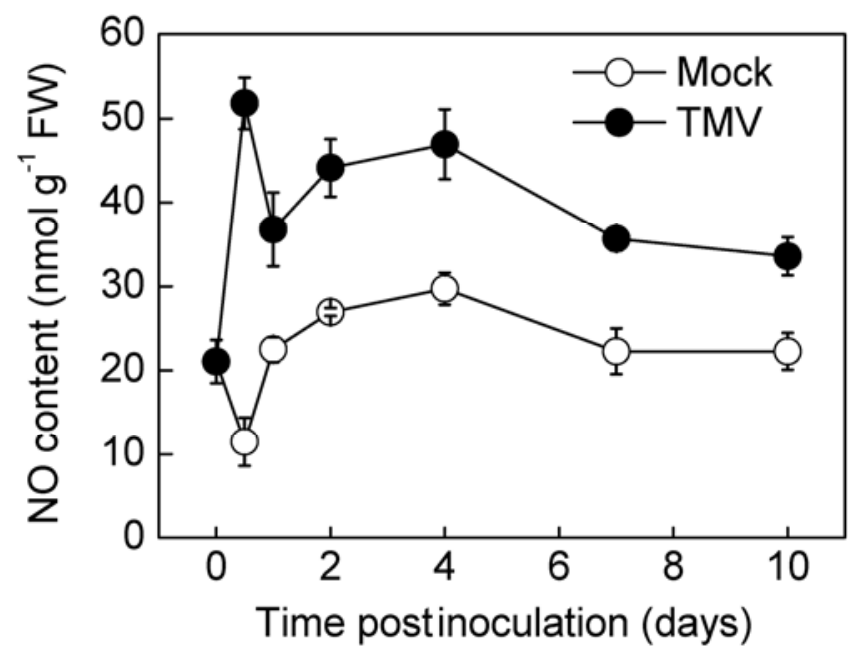

Fig. 2. Changes in leaf nitric oxide (NO) content in upper uninoculated leaves of tomato plants postinoculation with Tobacco mosaic virus (TMV) on a lower leaf. NO content was assayed with Greiss reagent at the time indicated. Open symbols indicate mock plants and closed symbols indicate TMV-inoculated plants. Results are mean values \pm standard deviation; $n=5$. suggest that $\mathrm{NO}$ is required for systemic induction of $\mathrm{AOX}$ by TMV.

\section{Levels of TMV susceptibility negatively correlate with AOX capacity in uninoculated tomato leaves.}

We next investigated whether NO-regulated AOX induction is part of TMV-induced defense response in tomato plants. Because TMV infection causes a reduction in operating efficiency of photosystem II (PSII), chlorophyll fluorescence imaging method was used to analyze the response of photochemical quantum yield at PSII ( $\left.\Phi_{\text {PSII }}\right)$ to AOX and NO chemical modulators in TMV-infected plants. At 10 dpi, pretreatment with $\mathrm{KCN}$, DEA/NO, or KCN+cPTIO all greatly increased $\Phi_{\text {PSII }}$ values when compared with unpretreated plants (Fig. 5 B, C, E, and G). In addition, the central leaves of pretreated plants did not show any symptoms of systemic infection. By contrast, pretreatment with SHAM or cPTIO substantially decreased $\Phi_{\mathrm{PSII}}$ and caused

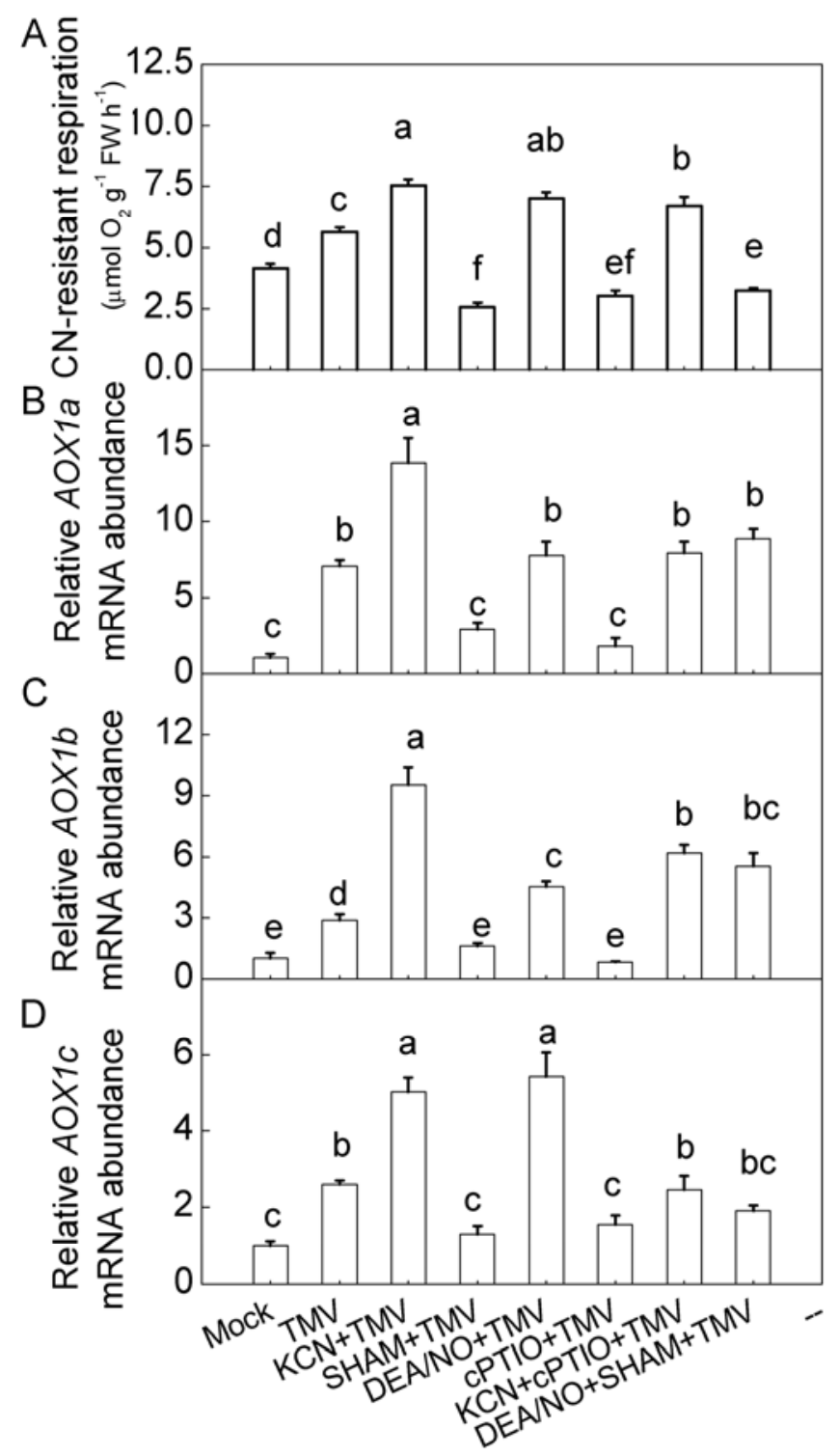

Fig. 3. A, Cyanide (CN)-resistant respiration and transcript levels of $\mathbf{B}$, alternative oxidase $(A O X 1) 1 a ; \mathbf{C}, A O X 1 b$; and $\mathbf{D}, A O X 1 c$ in upper uninoculated leaf of tomato plants. The upper uninoculated leaves were subjected to nitric oxide or AOX chemical modulator application for four successive days before Tobacco mosaic virus (TMV) inoculation. Leaf sample was collected at 4 days postinoculation. Results are mean values \pm standard deviation; $n=4$. Different letters depict significant differences between the treatments $(P<0.05)$. 
enhanced leaf necrotic lesions, crinkle, and distortion (Fig. 5B, $\mathrm{D}, \mathrm{F}$, and $\mathrm{H}$ ). Even though uninoculated leaves pretreated with DEA/NO+SHAM had higher $\Phi_{\mathrm{PSII}}$ than unpretreated plants, TMV challenge did lead to visible symptoms of systemic infection such as necrotic lesions, mosaics, and vein chlorosis (not shown). Furthermore, real-time quantitative RT-PCR was used to determine the TMV RNA accumulation after different treatments (Fig. 5I). Generally speaking, the results of transcript levels of $T M V$-coat protein $(C P)$ were in good agreement with those of chlorophyll fluorescence imaging analysis. Pretreatment with $\mathrm{KCN}$ and $\mathrm{DEA} / \mathrm{NO}$ resulted in an approximately fourfold reduction of $T M V-C P$ mRNA accumulation, whereas SHAM and cPTIO increased $T M V-C P$ transcripts by 264.2 and $65.1 \%$, respectively, compared with that in the unpretreated plants. While at the early stage of inoculation (at $4 \mathrm{dpi}$ ), $T M V$ $C P$ transcripts in the uninoculated leaves were very low and were not significantly different among the treatments (Fig. 5I). Thus, in upper uninoculated tomato leaves, NO contents and AOX capacity were associated with TMV susceptibility (Figs. 3 to 5), and $\mathrm{CN}$-resistant respiration was generally negatively correlated to the extent of TMV susceptibility.

\section{Effects of TMV inoculation and NO}

on mitochondrial aconitase activity, citrate content, and COX activities in uninoculated leaves.

To investigate the role of NO in TMV-induced AOX induction, we examined the mitochondrial aconitase (ACO) activity, citrate content of TCA cycle, and COX activities of the mitochondrial electron transport chain (Fig. 6). TMV infection resulted in inhibition of ACO activity by $38.0 \%$, which was increased to $55.7 \%$ if the TMV-inoculated plants were treated with DEA/NO but alleviated if treated with cPTIO. For mitochondrial citrate contents, a contrasting change was observed; TMV infection caused an increase in citrate content by $33.9 \%$, which was increased to $82.8 \%$ if pretreated with DEA/NO. There was no significant difference in ACO activity and mitochondrial citrate contents between mock inoculation and cPTIO+TMV treatment.

Similar to the change of ACO activity, TMV treatment led to a decrease in COX activity by $51.4 \%$, which was further decreased to $76.3 \%$ with DEA/NO pretreatment. However, this effect was completely abolished by the NO scavenger, and the COX activity in cPTIO pretreated plants was $91.5 \%$ higher
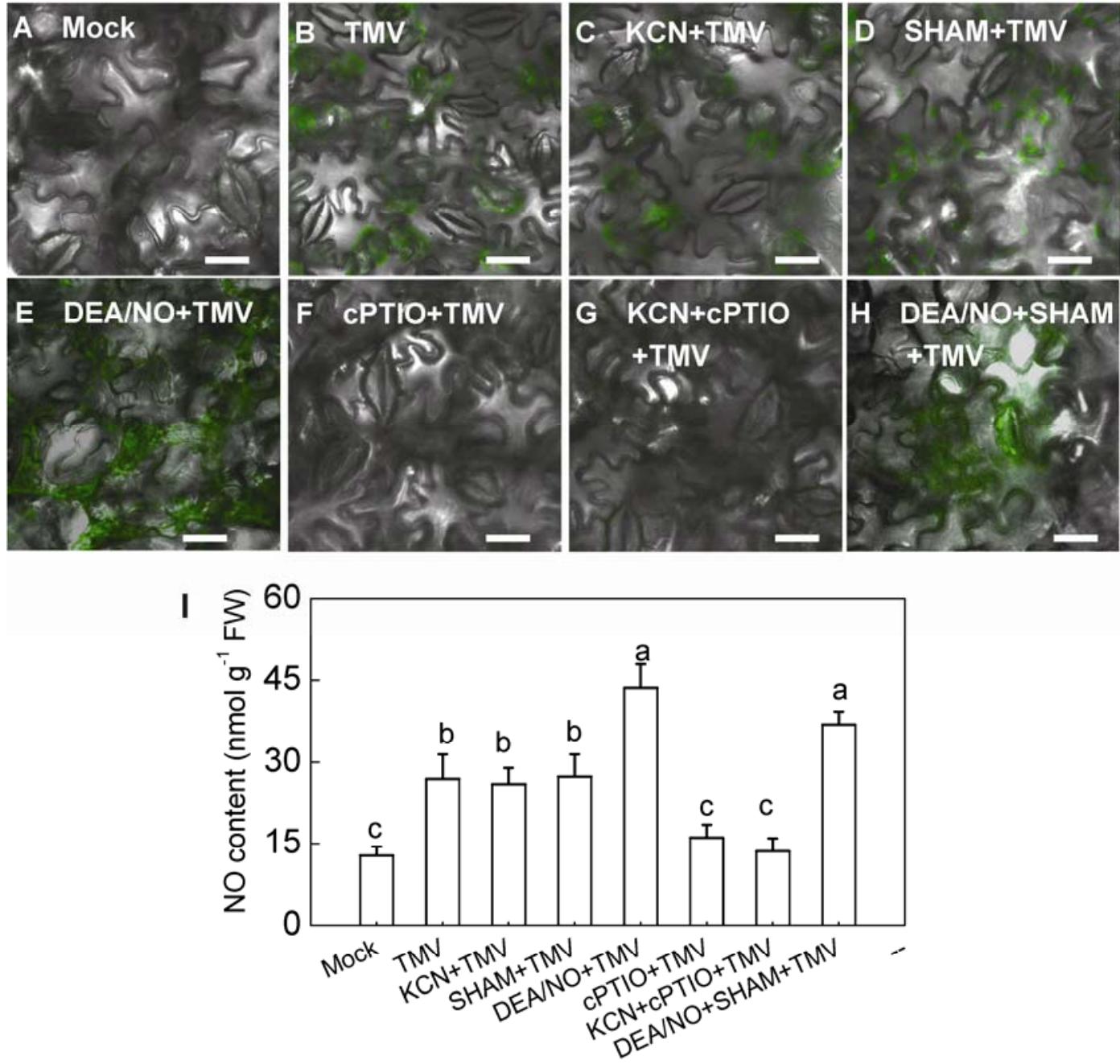

Fig. 4. Effects of different chemical pretreatments and Tobacco mosaic virus (TMV) infection on leaf nitric oxide (NO) contents in upper uninoculated leaves of tomato plants. The upper uninoculated leaves were subjected to NO or alternative oxidase (AOX) chemical modulator application for four successive days before TMV inoculation. The NO assay was made at 4 days postinoculation. A to $\mathbf{H}$, Representative NO visualization detected using diamine fluorescein diacetate (DAF-2DA) and a confocal microscope in which NO exhibits green fluorescence. The chemical pretreatment is shown above each image: A, Mock; B, TMV; C, $1 \mathrm{mM}$ potassium cyanide (KCN)+TMV; D, $3 \mathrm{mM}$ salicylhydroxamic acid (SHAM)+TMV; E, $1 \mathrm{mM}$ diethylamine NONOate (DEA/NO)+TMV; F, $0.2 \mathrm{mM}$ 2-(4-carboxyphenyl)-4,4,5,5-tetramethylimidazoline-1-oxyl-3-oxide (cPTIO)+TMV; G, $1 \mathrm{mM} \mathrm{KCN+0.2} \mathrm{mM}$ cPTIO+TMV; H, $1 \mathrm{mM} \mathrm{DEA/NO} \mathrm{+3} \mathrm{mM} \mathrm{SHAM+TMV.} \mathrm{All} \mathrm{images} \mathrm{are} \mathrm{at} \mathrm{the} \mathrm{same} \mathrm{magnification} \mathrm{and} \mathrm{the} \mathrm{white} \mathrm{scale} \mathrm{bar} \mathrm{indicates} 25 \mu \mathrm{m}$. I, NO contents assayed with Greiss reagent. Results are mean values \pm standard deviation; $n=4$. Different letters depict significant differences between the treatments $(P<0.05)$. 
than unpretreated plants and was comparable with that of mock-inoculated plants.

\section{DISCUSSION}

Increase in AOX gene expression or NO production is frequently observed in both compatible and incompatible plantpathogen interactions (Lennon et al. 1997; Chivasa and Carr
1998; Floryszak-Wieczorek et al. 2007; Love et al. 2007; Király et al. 2008). We showed that CN-resistant respiration and NO are increased within $12 \mathrm{~h}$ in upper uninoculated leaves of susceptible tomato plants after inoculation with TMV. Furthermore, TMV-induced AOX induction is enhanced by NO and blocked by NO scavenger. However, this TMV-induced NO production did not require AOX activation. Exogenous $\mathrm{KCN}$ - or $\mathrm{NO}$-induced $\mathrm{CN}$-resistant alternative respiration is
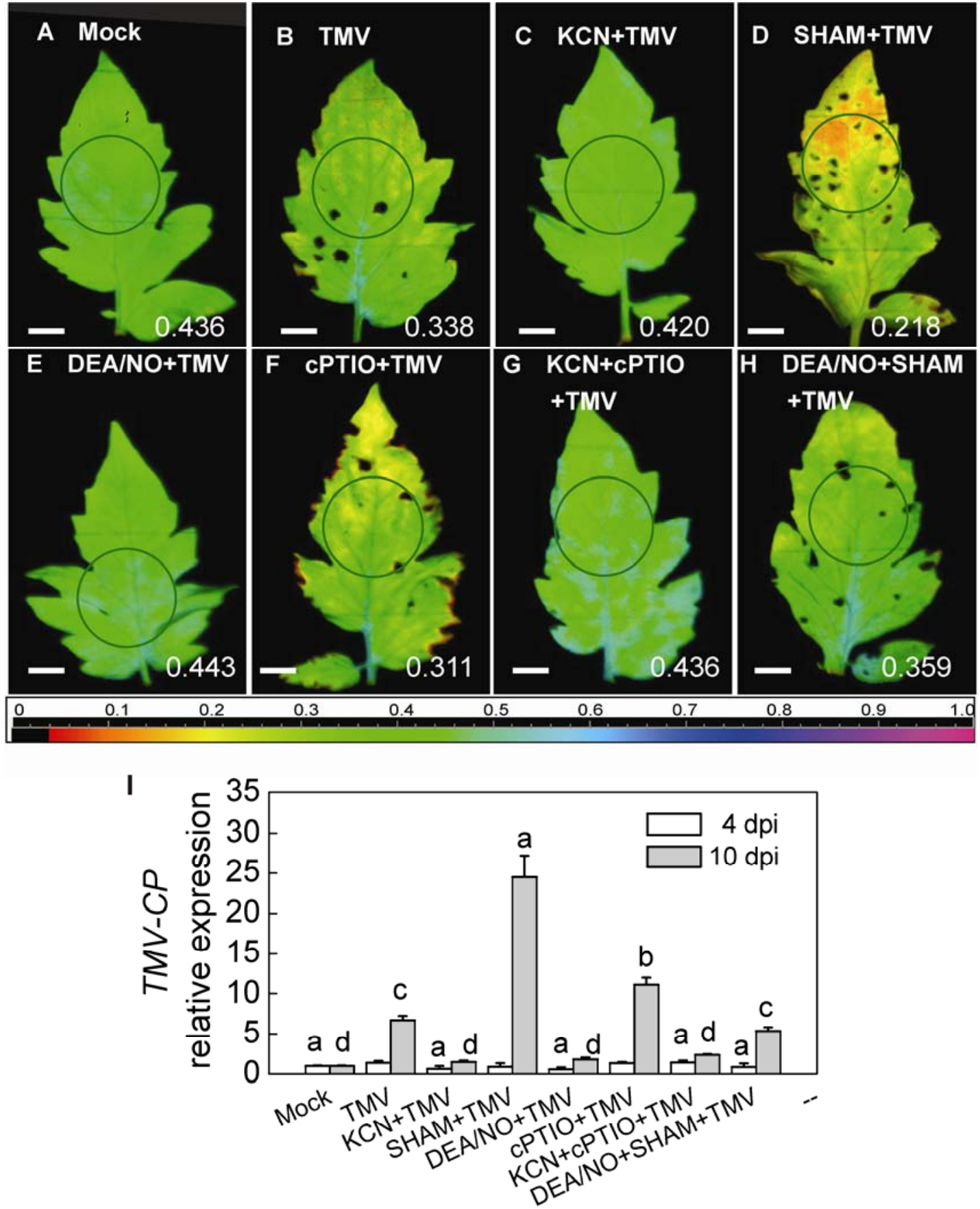

Fig. 5. Effects of different chemical pretreatments and Tobacco mosaic virus (TMV) infection on leaf photochemical quantum yield at photosystem II (PSII) $\left(\Phi_{\mathrm{PSII}}\right)$ and $T M V$-coat protein $(C P)$ gene transcription in upper uninoculated leaves of tomato plants. The upper uninoculated leaves were subjected to nitric oxide or alternative oxidase (AOX) chemical modulators application for four successive days before TMV inoculation. The $\Phi_{\text {PSII }}$ image was made at 10 days postinoculation whereas the $T M V-C P$ transcripts assay was made at both 4 and 10 days postinoculation. The chemical pretreatment is shown above each image. A to $\mathbf{H}$, Representative $\Phi_{\text {PSII }}$ images of from the IMAGING-PAM. A, Mock; B, TMV; C, $1 \mathrm{mM}$ potassium cyanide (KCN)+TMV; D, 3 mM salicylhydroxamic acid (SHAM)+TMV; E, $1 \mathrm{mM}$ diethylamine NONOate (DEA/NO)+TMV; F, $0.2 \mathrm{mM}$ 2-(4-carboxyphenyl)-4,4,5,5-tetramethylimidazoline-1oxyl-3-oxide (cPTIO)+TMV; G, $1 \mathrm{mM} \mathrm{KCN} \mathrm{+0.2} \mathrm{mM} \mathrm{cPTIO} \mathrm{+TMV;} \mathrm{H,} 1 \mathrm{mM}$ DEA/NO +3 mM SHAM+TMV. The circle in (A) to (H) indicates the spot where the fluorescence and aperture measurements were performed shown as the data in each figure. Scale bar $=0.5 \mathrm{~cm}$. The color gradient scale below indicates the magnitude of the fluorescence signal represented by each color. I, Transcript levels of $T M V$ - $C P$ gene by real-time reverse-transcription polymerase chain reaction. Results are mean values \pm standard deviation; $n=4$. Different letters depict significant differences between the treatments $(P<0.05)$. 
generally negatively correlated to levels of TMV susceptibility. Therefore, our results establish a connection between AOX and NO in regulation of a systemic antiviral defense response in tomato and show that $\mathrm{NO}$ acts upstream and mediates induction of AOX, which then contributes to limitation of virus systemic infection and accumulation.

\section{The role of AOX and NO in systemic basal defense to TMV in tomato plants.}

In this study, application of $\mathrm{KCN}$ and DEA/NO at nonlethal concentrations to uninoculated leaves can induce resistance to TMV and the resistance was totally antagonized by SHAM or cPTIO (Fig. 5). Increases in NO synthase (NOS)-like activity and the role of NO in systemic acquired resistance have been studied previously in tobacco plants challenged with TMV (Durner et al. 1998; Klessig et al. 2000; Song and Goodman 2001) and in Arabidopsis plants inoculated with Pseudomonas syringae (Feechan et al. 2005; Tada et al. 2008). Our results

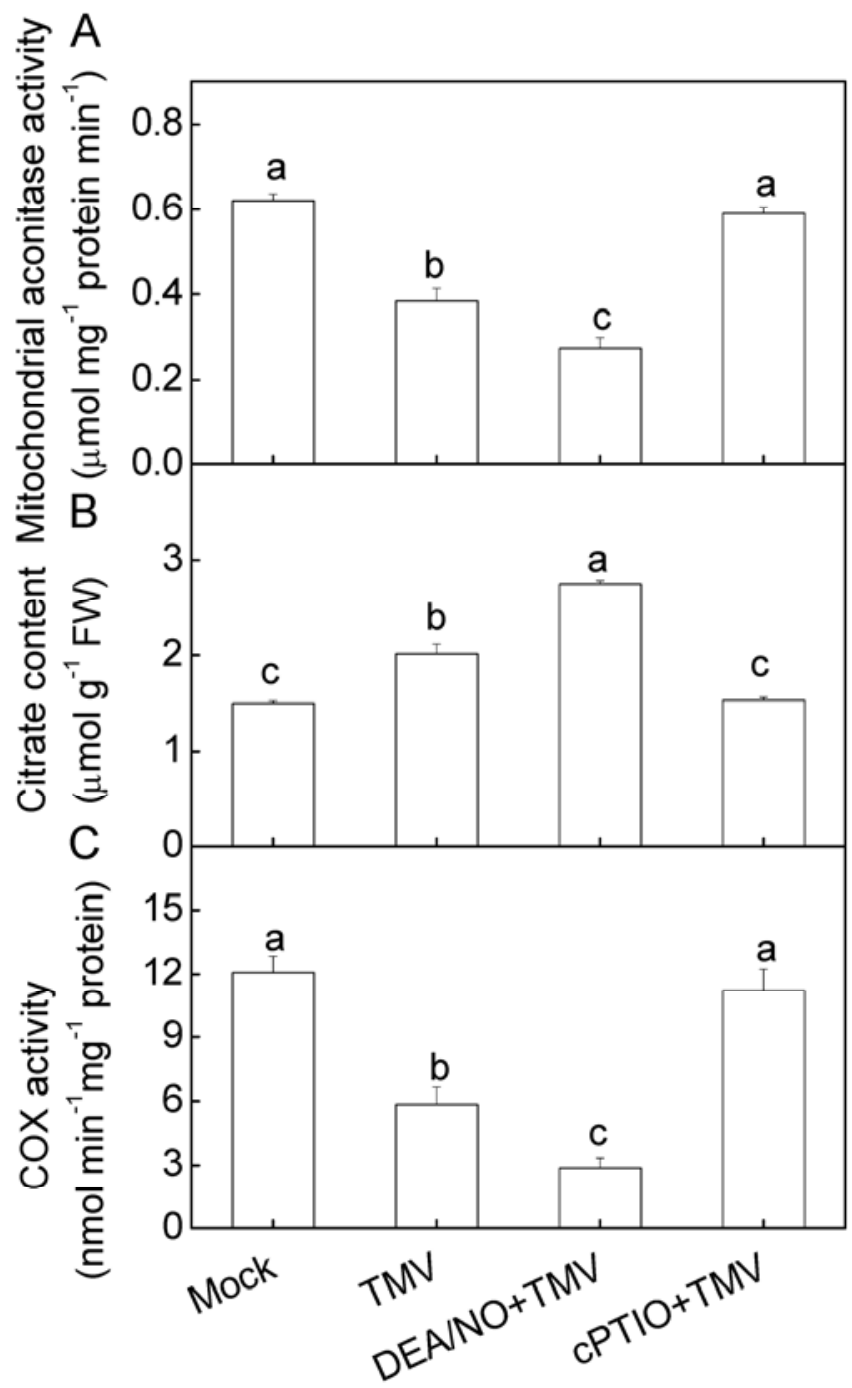

Fig. 6. Effects of Tobacco mosaic virus (TMV) infection and pretreatments with diethylamine NONOate (DEA/NO) and 2-(4-carboxyphenyl)4,4,5,5-tetramethylimidazoline-1-oxyl-3-oxide (cPTIO) on A, mitochondrial aconitase activity; $\mathbf{B}$, citrate content; and $\mathbf{C}$, cytochrome $c$ oxidase $(\mathrm{COX})$ activity in upper uninoculated leaves of tomato plants. The upper uninoculated leaves were subjected to DEA/NO and cPTIO application for four successive days before TMV inoculation. Leaf sample was collected at 4 days postinoculation. Results are mean values \pm standard deviation; $n=4$. Different letters depict significant differences between the treatments $(P<0.05)$. further support the hypothesis that NO plays an important role in plant defense responses. However, there has been no conclusive evidence for $\mathrm{CN}$-resistant respiration in systemic basal defense against viral pathogens. In this work, we found that systemic TMV infection could be diminished by $\mathrm{KCN}$ and enhanced by the AOX inhibitor and that KCN could fully alleviate cPTIO-induced $\Phi_{\text {PSII }}$ decrease and $T M V-C P$ accumulation (Fig. 5). Most importantly, both AOX and $\mathrm{CN}$-resistant respiration appeared to be negatively correlated to the magnitude of TMV susceptibility (Figs. 3 and 5). In accordance with this result, SHAM treatment accelerated compatible Cauliflower mosaic virus (CaMV) spread in Arabidopsis and partially restored susceptibility of several mutants to wild-type levels (Love et al. 2007). Our results, together with previous observations, suggest that AOX induction contribute positively to systemic basal defense against viral pathogens in plants (Chivas and Carr 1998; Naylor et al. 1998; Singh et al. 2004).

As in environmental stresses such as chilling, ozone, or treatment with exogenous elicitors such as harpin, the potential means by which AOX acts on virus attack is by modulating mitochondrial (or cellular) redox and reducing ROS production (Murphy et al. 1999; Ederli et al. 2006; Noctor et al. 2006; Vidal et al. 2007; Watanabe et al. 2008). AOX lowers buildup of ROS in the mitochondria by preventing over-reduction of the cytochrome respiratory electron transport chain and the ubiquinone pool (Maxwell et al. 1999; Navrot et al. 2007). The AOX-mediated changes in ROS production or cellular redox status may regulate the activity of downstream elements in the SHAM-sensitive pathway. This model is based on the observation that the Nicotiana sylvestris mitochondria mutants, which have elevated levels of AOX protein, have an altered redox status, and expression of antioxidant enzymes showed enhanced TMV resistance with reduced number and size of lesions (Dutilleul et al. 2003). However, overproduction of wild-type or mutant AOX protein accelerated systemic movement of TMV in N. benthamiana (Murphy et al. 2004). These results indicate that abnormal levels of AOX proteins could perturb the mitochondrial redox balance, which then compromises plant defense against virus (Király et al. 2008). In addition, AOX induction did not induce resistance to CMV in squash (Mayers et al. 2005). In Arabidopsis, if antimycin A treatment and viral inoculation were on separate leaves, the plant susceptibility to compatible CaMV was not reduced, even though inoculation of virus and treatment of antimycin A on the same leaf effectively induced Arabidopsis resistance to CaMV (Love et al. 2005). Therefore, discrepancy between these reports and our results suggest that different host species might use different approaches in defense against different viral pathogens.

\section{Interrelationship between systemic AOX induction and NO generation in response to TMV inoculation.}

In this study, we observed that treatment with DEA/NO and cPTIO resulted in AOX induction and suppression, respectively, and that the levels of virus susceptibility could be antagonized by SHAM and KCN (Figs. 3 and 5). These observations suggest a possible connection between AOX and NO in modulating defense response. Previously, it was found that AOXIa expression and CN-resistant respiration were strongly induced in Arabidopsis cell cultures after treatment with NO (Huang et al. 2002). Similarly, Ederli and associates (2006) also demonstrated that, in $\mathrm{O}_{3}$-fumigated tobacco plants, NOdependent pathway was required for $\mathrm{O}_{3}$-induced upregulation of AOXla. However, mitochondrial electron transport and AOX pathway were identified as major sources of NO synthesis because strong inhibition of NO generation was achieved by SHAM in N. tabacum and unicellular green alga Chlorella 
sorokiniana (Tischner et al. 2004; Planchet et al. 2005). These results suggest that there is a cross-talk between NO and AOX in plant cells in response to stresses or stimuli. In the present study, our data suggest that NO acts upstream of TMVinduced AOX induction. First, time-course analysis of NO generation and AOX induction showed that the increase in NO generation preceded AOX induction in response to TMV infection (Figs. 1 and 2). Second, DEA/NO significantly increased transcript levels of $A O X$ genes, and pretreatment with cPTIO almost fully blocked TMV-induced upregulation of AOX gene expression and $\mathrm{CN}$-resistant respiration (Fig. 3). By contrast, pretreatments with an AOX inhibitor had little effect on NO production (Fig. 4). Therefore, it is most likely that TMV-induced NO triggers AOX induction, and this induced AOX then plays a role in regulating systemic basal defense response against TMV.

The mobile signals involved in the systemic defensive system is unclear but may not be the virus itself because, at $4 \mathrm{dpi}$ the $T M V-C P$ mRNA accumulation in the uninoculated leaf tissue did not differ between treatments (Fig. 5I), which is consistent with previously reported leaf removal experiments (Love et al. 2005). Furthermore, tobacco epidermal cells respond to both incompatible and compatible isolates of TMV within seconds of exposure (Allan et al. 2001). An ROS burst occurs both locally and systemically within 2 to $6 \mathrm{~h}$ of inoculation with compatible CaMV to Arabidopsis (Love et al. 2005). In the present study, TMV inoculation to the lower leaves induced a rapid NO synthesis and AOX activation in upper uninoculated leaves as early as 0.5 dpi (Figs. 1 and 2). Therefore, in addition to NO and AOX, ROS might be involved in the systemic defensive system.

It should be noted that the DEA/NO-induced TMV resistance was not fully abolished by SHAM (Fig. 5); thus, an additional unknown AOX-independent pathway in the NO signaling pathway might exist. In addition, several lines of evidence pointed out that SA, ethylene (ET), and other signaling molecules may also be involved in AOX induction (Lennon et al. 1997; Norman et al. 2004; Ederli et al. 2006). However, NO-induced AOX was not affected after treatment with NO in the pad4 and nprl mutants and in the transgenic NahG plants (Huang et al. 2002); antimycin A-induced resistance to CaMV was not affected in $N a h G$ plant and ET-signaling mutant etrl (Love et al. 2007). Therefore, it is likely that SA, NO, and ET act synergistically or independently in AOX induction. Accordingly, further experiments are required to fully establish the relationship between SA, NO, ET, and their possible functions in AOX induction and TMV resistance.

\section{Potential mechanism of NO on AOX induction under TMV-inoculated conditions.}

How the TMV-induced NO regulates induction of AOX and the alternative pathway respiratory $\mathrm{O}_{2}$ uptake is unclear. NOmediated expression of defense genes in plants is through both cyclic guanosine monophosphate (cGMP)-dependent and cGMP-independent pathways, the latter involving the activation of thiol-containing proteins and Tyr nitration, or through the direct interaction of $\mathrm{NO}$ with metal-containing proteins (Kroncke et al. 1997). Thus, NO-induced AOX in mitochondria may involve a mechanism by which NO targets the ironsulfur cluster-dependent enzymes ACO of the TCA cycles, or the heme-containing enzyme COX, the Cyt pathway terminal member of the mitochondrial electron transport (Millar and Day 1996; Navarre et al. 2000). In our study, both mitochondrial ACO and COX activity was inhibited by TMV and this inhibition was significantly enhanced by DEA/NO and eliminated by cPTIO (Fig. 6). ACO catalyzes the reversible isomerization of citrate to isocitrate; thus, inactivation of $\mathrm{ACO}$ not only affects mitochondrial energy metabolism but also results in elevated citrate concentrations (Shlizerman et al. 2007). Interestingly, exogenous application of citrate to tobacco suspension cells caused a rapid and dramatic increase in the steadystate level of Aoxl mRNA and AOX protein (Vanlerberghe and McIntosh 1996). The elevated citrate content might play a role in TMV-induced AOX induction in the present study. In addition, COX has been reported as another primary target of NO because endogenous NO inhibited cytochrome $c$-dependent respiration but not the AOX in isolated soybean mitochondria (Millar and Day 1996; Yamasaki et al. 2001). The alternative respiratory pathway was subsequently induced to maintain energy metabolism and ubiquinone pool at low steady-state poise when electron flow through the Cyt pathway is restricted (Millar and Day 1996, 1997). Because a direct interaction between NO and AOX appear unlikely, it is possible that AOX may act as a cellular component to receive the NO signal indirectly. This hypothesis is supported by previous observations that activation of the NO-tolerant alternative respiratory pathway could dampen the generation of ROS and maintain mitochondrial (or cellular) function when NO-sensitive ACO and COX were inhibited (Millar and Day 1997; Maxwell et al. 1999). This might be a role of AOX during plant-virus interactions. It should be mentioned that antioxidant induction has also been suggested to play important roles in virus-induced plant defense reactions (Király et al. 2002; Després et al. 2003). Therefore, reduction of ROS accumulation during virus attacks might be achieved by both AOX (elimination of ROS production) and antioxidants (elimination of ROS production).

In summary, we demonstrated in this study that mitochondrial AOX and NO crosstalk in induction of antiviral defense response in tomato uninoculated leaves against TMV infection. The results suggest that TMV-induced NO generation acts upstream and mediates AOX induction, which might then modulate mitochondrial (or cellular) redox and reduce ROS production, thus limiting virus systemic infection and accumulation.

\section{MATERIALS AND METHODS}

\section{Plants, virus, and chemical treatments.}

Tomato (Solanum lycopersicum L. cv. Hezuo 903, TMV susceptible) plants were grown in a greenhouse at 25 and $20^{\circ} \mathrm{C}$ (day and night air temperature, respectively) with a 16-h photoperiod. Three upper fully developed leaves of four- to fiveleaf-stage seedlings were used for chemical pretreatment, and the lower fully developed leaves were used for inoculation with TMV 4 days after chemical pretreatment. Stock solutions of cPTIO and KCN were prepared fresh weekly in $20 \mathrm{mM}$ potassium phosphate buffer, $\mathrm{pH}$ 6.8, and SHAM was dissolved in deionized water. A stock solution of DEA/NO was made in $10 \mathrm{mM} \mathrm{NaOH}$ on ice and prepared daily. To initiate the release of NO, an aliquot of the stock alkaline solution was dissolved in $10 \mathrm{mM}$ phosphate buffer, $\mathrm{pH} 7.4$, to give a $1-\mathrm{mM}$ final concentration. Tomato plants were sprayed with water or freshly diluted solutions of $1 \mathrm{mM} \mathrm{KCN}, 3 \mathrm{mM}$ SHAM, $1 \mathrm{mM}$ DEA/NO, $0.2 \mathrm{mM}$ cPTIO, $1 \mathrm{mM}$ KCN plus $0.2 \mathrm{mM}$ cPTIO, or $1 \mathrm{mM}$ DEA/NO plus $3 \mathrm{mM}$ SHAM daily in both the adaxial and abaxial surface. Four days later, the lower fully developed leaf of each plant was inoculated with the U1 strain of TMV. Viral inoculum was prepared in $5 \mathrm{mM}$ potassium phosphate buffer, $\mathrm{pH} \mathrm{7.2,} \mathrm{at} 6 \mu \mathrm{g} \mathrm{ml} \mathrm{m}^{-1}$. For inoculation, the plants were sprayed with Carborundum and then inoculated by rubbing $100 \mu \mathrm{l}$ of viral inoculum onto each leaf with cotton swabs. Mock-inoculation controls were prepared using the same procedure with buffer. The upper newly developed uninoculated leaves were collected at different time points as indicated for 
leaf respiration and internal NO content assays. Unless otherwise stated, the physiological and molecular measurements were carried out 4 dpi and the chlorophyll fluorescence imaging was made at $10 \mathrm{dpi}$, while $T M V-C P$ gene transcription analysis were made both at 4 and 10 dpi. Experiments were independently carried out three times.

\section{Respiration in uninoculated leaves.}

Respirations of leaves were measured following the method of Millenaar and associates (2002) using a Clark-type oxygen electrode (Hansatech, King's Lyn, U.K.) at different days postinoculation. Plants were kept in darkness for $15 \mathrm{~min}$ before respiration measurement and leaves were detached and cut into pieces with a razor blade. Leaf samples $(0.1 \mathrm{~g})$ were transferred to air-tight cuvettes containing $2 \mathrm{ml}$ of air-saturated 20 $\mathrm{mM}$ potassium phosphate buffer $(\mathrm{pH} 6.8)$ and respiration was measured as a decrease of $\mathrm{O}_{2}$ concentration at $25^{\circ} \mathrm{C}$. CN-resistant respiration was measured in the presence of $1 \mathrm{mM} \mathrm{KCN}$.

\section{RNA extraction and transcript level estimation by real-time quantitative PCR.}

Total RNA was extracted using the TRIzol reagent (Invitrogen, Carlsbad, CA, U.S.A.) according to the manufacturer's specifications. Genomic DNA was removed using the RNeasy mini kit (Qiagen, Hilden, Germany). Complementary DNA was synthesized using $2 \mu \mathrm{g}$ of RNA with the RevertAid firststrand cDNA synthesis kit (Fermentas, Vilnius, Lithuania). Gene-specific primers were designed for analyzing transcript levels of each member of the AOX family. TMV-specific primers were also designed based on the sequence encoding the $T M V-C P$. The primers used for the amplification of each cDNA are listed in Table 1.

RT-PCR was performed with an iCycler iQ Multicolor RealTime PCR Detection System (Bio-Rad, Hercules, CA, U.S.A.). Each reaction (20- $\mu$ l total volume) consisted of $10 \mu \mathrm{l}$ of iQ SYBR Green Supermix, $1 \mu$ l of diluted cDNA, and 0.1 $\mu \mathrm{M}$ each of forward and reverse primers. PCR cycling conditions were as follows: $95^{\circ} \mathrm{C}$ for $3 \mathrm{~min}$, followed by 40 cycles of $95^{\circ} \mathrm{C}$ for $10 \mathrm{~s}$ and $58^{\circ} \mathrm{C}$ for $45 \mathrm{~s}$. Fluorescence data were collected during the $58^{\circ} \mathrm{C}$ step. The tomato actin gene was used as an internal control. Relative gene expression was calculated as described by Livak and Schmittgen (2001).

\section{Measuring NO accumulation.}

NO detection by a CLSM system was carried out essentially following the method of Corpas and associates (2004) with minor modifications. Leaf sections $(0.5$ by $0.5 \mathrm{~cm})$ were taken using a razor blade from the studied leaves and incubated in the dark for $30 \mathrm{~min}$ at $25^{\circ} \mathrm{C}$ in $10 \mathrm{mM}$ Tris- $\mathrm{HCl}(\mathrm{pH}$ 7.4) containing $10 \mu \mathrm{M}$ 4,5-diaminofluorescein diacetate (DAF-2DA) (Sigma-Aldrich, St. Louis). After washing twice in fresh buffer for $15 \mathrm{~min}$ each, the leaf sections were mounted in the same buffer on microscope slides and then examined immediately under a CLSM system (Leica TCS SP5; Leica Microsystems, Wetzlar, Germany). The sections were excited with the 488-nm line of an argon laser and dye emissions were recorded using a 505- to 530-nm band-pass filter. Background staining was controlled with leaf sections unstained or preincubated with $1 \mathrm{mM}$ cPTIO $\left(1 \mathrm{~h}, 25^{\circ} \mathrm{C}\right)$, a $\mathrm{NO}$ scavenger. In addition, NO was also determined with Greiss reagent (Sigma-Aldrich) following the method of Zhou and associates (2005).

\section{Chlorophyll fluorescence imaging.}

Leaves used for chlorophyll fluorescence assay were collected 10 dpi so that infection of TMV could be analyzed with the MAXI version of the IMAGING-PAM M-Series chlorophyll fluorescence system (Heinz-Walz GmbH, Effeltrich, Germany). This system allows noninvasive determination of the quantum efficiency of PSII by the saturation pulse method (Genty et al. 1989). Saturation pulses were given every $20 \mathrm{~s}$ and $\Phi_{\text {PSII }}$ was calculated as $\left(F_{\mathrm{m}}{ }^{\prime}-F_{\mathrm{t}}\right) / F_{\mathrm{m}}{ }^{\prime}$ (Genty et al. 1989).

\section{Enzyme activities and citric acid content assays.}

ACO activity was determined with mitochondrial fractions following the protocol for mitochondria isolation by Mittova and associates (2000) with some modifications as described previously (Shi et al. 2008). After mitochondria were isolated and broken up, ACO was purified according to Navarre and associates (2000) and was measured spectrophotometrically at $240 \mathrm{~nm}$ by monitoring formation of cis-aconitate from isocitrate (Kennedy et al. 1983). The assay was performed at room temperature in $75 \mathrm{mM}$ Tris- $\mathrm{Cl}(\mathrm{pH} 8.0)$ containing $30 \mathrm{mM}$ DL-trisodium isocitrate. An extinction coefficient for cis-aconitate of $3.6 \mathrm{mM}^{-1} \mathrm{~cm}^{-1}$ at $240 \mathrm{~nm}$ was used. COX activity (EC 1.9.3.1) was measured at $550 \mathrm{~nm}\left(25^{\circ} \mathrm{C}\right)$ in the presence of 20 $\mu \mathrm{M}$ reduced cytochrome $c$ in $10 \mathrm{mM}$ phosphate buffer $(\mathrm{pH}$ 7.2) according to Millenaar and associates (2002).

Citric acid content in leaf tissue was analyzed by high performance liquid chromatography (HPLC) as described by Suárez and associates (2008). Samples $(10 \mu \mathrm{l})$ were loaded onto the Waters HPLC System (Waters Corporation, Milford, MA, U.S.A.) with a spherisorb C18 column (4.6 by $250 \mathrm{~mm}$ ). Temperature of the column was set at $T=35^{\circ} \mathrm{C}$ during all of the experiments. The mobile phase was $20 \mathrm{mM} \mathrm{KH}_{2} \mathrm{PO}_{4}$, adjusted $\mathrm{pH}$ to 2.5 with concentrated $\mathrm{H}_{3} \mathrm{PO}_{4}$ at a flow rate of 1

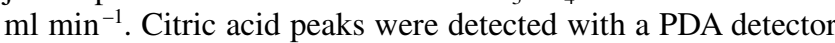
at $210 \mathrm{~nm}$.

\section{Statistical methods.}

There were at least three independent replicates for each determination. Data were subjected to analysis of variance and the means were compared using Tukey's test at $5 \%$ level.

Table 1. Primers used for real time reverse-transcription polymerase chain reaction assays

\begin{tabular}{|c|c|c|c|}
\hline Gene & Encoding protein & Accession no. & Primer pairs \\
\hline \multirow[t]{2}{*}{$T M V-C P$} & Tobacco mosaic virus coat protein & V01408.1 & F: 5'-TTCTTGTCATCAGCGTGGGC-3' \\
\hline & $\ldots$ & $\ldots$ & R: 5'-TTCGGCAGTCGTGGGGTTC-3' \\
\hline \multirow[t]{2}{*}{ AOXIa } & Alternative oxidase 1a & AY034148.1 & F: 5'-TCATTACCAAGGACAACAGC-3' \\
\hline & & & R: 5'-GGAACAAAATAGTGACGGAC-3' \\
\hline \multirow{2}{*}{$A O X 1 b$} & Alternative oxidase $1 \mathrm{~b}$ & AY034149.1 & F: 5'-TCCTCCACTGTAAATCCC-3' \\
\hline & & & R: 5'-AAATACGCCTTGAACTGC-3' \\
\hline \multirow[t]{2}{*}{$A O X 1 c$} & Alternative oxidase $1 \mathrm{c}$ & AY324397.1 & F: 5'-TAAGGCGATTCGAGCACA-3' \\
\hline & 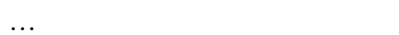 & $\ldots$ & R: 5'-CCATTAAGACAAGTCCACGT-3' \\
\hline \multirow[t]{2}{*}{$A O X 2$} & Alternative oxidase 2 & AY324396.1 & F: 5'-ATGATATTGATCGTGGTGA-3' \\
\hline & $\ldots$ & $\ldots$ & R: 5'-TCCTTAGGCAGTCTCCA-3' \\
\hline \multirow[t]{2}{*}{ Actin } & $\ldots$ & U60481.1 & F: 5'-TGTCCCTATTTACGAGGGTTATGC-3' \\
\hline & $\ldots$ & $\ldots$ & R: 5'-CAGTTAAATCACGACCAGCAAGAT-3' \\
\hline
\end{tabular}




\section{ACKNOWLEDGMENTS}

We thank Z. Chen of Purdue University for his critical reading of the manuscript. This work was supported by the National Basic Research Program of China (2009CB119000), National Natural Science Foundation of China (30800763), the China Postdoctoral Science Foundation funded project (20070420237 and 20081464), and the National Key Technology R\&D Program of China (2008BADA6B02).

\section{LITERATURE CITED}

Allan, A. C., Lapidot, M., Culver, J. N., and Fluhr, R. 2001. An early tobacco mosaic virus-induced oxidative burst in tobacco indicates extracellular perception of the virus coat protein. Plant Physiol. 126:97-108.

Amirsadeghi, S., Robson, C. A., and Vanlerberghe, G. C. 2007. The role of the mitochondrion in plant responses to biotic stress. Physiol. Plant. 129:253-266.

Arnholdt-Schmitt, B., Costa, J. H., and de Melo, D. F. 2006. AOX-a functional marker for efficient cell reprogramming under stress? Trends Plant Sci. 11:281-287.

Asai, S., Ohta, K., and Yoshioka, H. 2008. MAPK signaling regulates nitric oxide and NADPH oxidase-dependent oxidative bursts in Nicotiana benthamiana. Plant Cell 20:1390-1406.

Avila-Adame, C., and Köller, W. 2002. Disruption of the alternative oxidase gene in Magnaporthe grisea and its impact on host infection. Mol. Plant-Microbe Interact. 15:493-500.

Chivasa, S., and Carr, J. P. 1998. Cyanide restores $N$ gene-mediated resistance to tobacco mosaic virus in transgenic tobacco expressing salicylic acid hydroxylase. Plant Cell 10:1489-1498.

Chivasa, S., Murphy, A. M., Naylor, M., and Carr, J. P. 1997. Salicylic acid interferes with tobacco mosaic virus replication via a novel salicylhydroxamic acid-sensitive mechanism. Plant Cell 9:547-557.

Corpas, F. J., Barroso, J. B., Carreras, A., Quirós, M., León, A. M., Romero-Puertas, M. C., Esteban, F. J., Valderrama, R., Palma, J. M., Sandalio, L. M., Gómez, M., and del Río, L. A. 2004. Cellular and subcellular localization of endogenous nitric oxide in young and senescent pea plants. Plant Physiol. 136:2722-2733.

Després, C., Chubak, C., Rochon, A., Clark, R., Bethune, T., Desveaux, D., and Fobert, P. R. 2003. The Arabidopsis NPR1 disease resistance protein is a novel cofactor that confers redox regulation of DNA binding activity to the basic domain/leucine zipper transcription factor TGA1. Plant Cell 15:2181-2191.

Durner, J., Wendehenne, D., and Klessig, D. F. 1998. Defense gene induction in tobacco by nitric oxide, cyclic GMP and cyclic ADP ribose. Proc. Natl. Acad. Sci. U.S.A. 95:10328-10333.

Dutilleul, C., Garmier, M., Noctor, G., Mathieu, C., Chetrit, P., Foyer, C. H., and De Paepe, R. 2003. Leaf mitochondria modulate whole cell redox homeostasis, set antioxidant capacity, and determine stress resistance through altered signaling and diurnal regulation. Plant Cell 15:1212-1226.

Ederli, L., Morettini, R., Borgogni, A., Wasternack, C., Miersch, O., Reale, L., Ferranti, F., Tosti, N., and Pasqualini, S. 2006. Interaction between nitric oxide and ethylene in the induction of alternative oxidase in ozone-treated tobacco plants. Plant Physiol. 142:595-608.

Feechan, A., Kwon, E., Yun, B. W., Wang, Y., Pallas, J. A., and Loake, G. J. 2005. A central role for $S$-nitrosothiols in plant disease resistance. Proc. Natl. Acad. Sci. U.S.A. 102:8054-8059.

Floryszak-Wieczorek, J., Arasimowicz, M., Milczarek, G., Jelen, H., and Jackowiak, H. 2007. Only an early nitric oxide burst and the following wave of secondary nitric oxide generation enhanced effective defence responses of pelargonium to a necrotrophic pathogen. New Phytol. $175: 718-730$

Gális, I., Smith, J. L., and Jameson, P. E. 2004 Salicylic acid-, but not cytokinin-induced, resistance to WCIMV is associated with increased expression of SA-dependent resistance genes in Phaseolus vulgaris. J. Plant Physiol. 161:459-466.

Genty, B., Briantais, J. M., and Baker, N. R. 1989. The relationship between the quantum yield of photosynthetic electron transport and quenching of chlorophyll fluorescence. Biochim. Biophys. Acta 990:87-92.

Huang, X., von Rad, U., and Durner, J. 2002. Nitric oxide induces transcriptional activation of the nitric oxide-tolerant alternative oxidase in Arabidopsis suspension cells. Planta 215:914-923.

Kachroo, P., Yoshioka, K., Shah, J., Dooner, H. K., and Klessig, D. F. 2000. Resistance to turnip crinkle virus in Arabidopsis is regulated by two host genes and is salicylic acid dependent but NPR1, ethylene, and jasmonate independent. Plant Cell 12:677-690.

Kennedy, M. C., Emptage, M. H., Dreyer, J. L., and Beinert, H. 1983. The role of iron in the activation-inactivation of aconitase. J. Biol. Chem.
258:11098-11105

Király, Z., Barna, B., Kecskés, A., and Fodor, J. 2002. Down-regulation of antioxidative capacity in a transgenic tobacco which fails to develop acquired resistance to necrotization caused by TMV. Free Radic. Res. 36:981-991.

Király, L., Hafez, Y. M., Fodor, J., and Király, Z. 2008. Suppression of tobacco mosaic virus-induced hypersensitive-type necrotization in tobacco at high temperature is associated with downregulation of NADPH oxidase and superoxide and stimulation of dehydroascorbate reductase. J. Gen. Viol. 89:799-808.

Klessig, D. F., Durner, J., Noad, R., and Navarre, D. A., Wendehenne, D., Kumar, D., Zhou, J. M., Shah, J., Zhang, S. Q., Kachroo, P., Trifa, Y., Pontier, D., Lam, E., and Silva, H. 2000. Nitric oxide and salicylic acid signaling in plant defense. Proc. Natl. Acad. Sci. U.S.A. 97:8849-8855.

Krause, M., and Durner, J. 2004. Harpin inactivates mitochondria in Arabidopsis suspension cells. Mol. Plant-Microbe Interact. 17:131-139.

Kroncke, K.D., Fehsel, K., and Kolb-Bachofen, V. 1997. Nitric oxide: cytotoxicity versus cytoprotection: how, why, when, and where? Nitric Oxide Biol. Chem. 1:107-120

Lennon, A. M., Neuenschwander, U., Ribas-Carbo, M., Giles, L., Ryals, J. A., and Siedow, J. N. 1997. The effects of salicylic acid and tobacco mosaic virus infection on the alternative oxidase of tobacco. Plant Physiol. 115:783-791.

Livak, K. J., and Schmittgen, T. D. 2001. Analysis of relative gene expression data using real-time quantitative PCR and the $2\left(-\Delta \Delta \mathrm{C}_{\mathrm{t}}\right)$ method. Methods 25:402-408.

Love, A. J., Yun, B. W., Laval, V., Loake, G.. J., and Milner, J. J. 2005. Cauliflower mosaic virus, a compatible pathogen of Arabidopsis, engages three distinct defense-signaling pathways and activates rapid systemic generation of reactive oxygen species. Plant Physiol. 139:935948.

Love, A. J., Laval, V., Geri, C., Laird, J., Tomos, A. D., Hooks, M. A., and Milner, J. J. 2007. Components of Arabidopsis defense- and ethylenesignaling pathways regulate susceptibility to Cauliflower mosaic virus by restricting long-distance movement. Mol. Plant-Microbe Interact. 20:659-670.

Maxwell, D. P., Wang, Y., and McIntosh, L. 1999. The alternative oxidase lowers mitochondrial reactive oxygen production in plant cells. Proc. Natl. Acad. Sci. U.S.A. 96:8271-8276.

Mayers, C. N., Lee, K. C., Moore, C. A., Wong, S. M., and Carr, J. P. 2005. Salicylic acid-induced resistance to Cucumber mosaic virus in squash and Arabidopsis thaliana: Contrasting mechanisms of induction and antiviral action. Mol. Plant-Microbe Interact. 18:428-434.

Millar, A. H., and Day, D. A. 1996. Nitric oxide inhibits the cytochrome oxidase but not the alternative oxidase of plant mitochondria. FEBS (Fed. Eur. Biochem. Soc.) Lett. 398:155-158.

Millar, A. H., and Day, D. A. 1997. Alternative solutions to radical problems. Trends Plant Sci. 2:289-290.

Millenaar, F. F., Gonzalez-Meler, M. A., Siedow, J. N., Wagner, A. M., and Lambers, H. 2002. Role of sugars and organic acids in regulating the concentration and activity of the alternative oxidase in Pоа аппиа roots. J. Exp. Bot. 53:1081-1088.

Mittova, V., Volokita, M., Guy, M., and Tal, M. 2000. Activities of SOD and the ascorbate-glutathione cycle enzymes in subcellular compartments in leaves and roots of the cultivated tomato and its wild salt-tolerant relative Lycopersicon pennellii. Physiol. Plant. 110:42-51.

Moore, A. L., Albury, M. S., Chrichton, P. G., and Affourtit, C. 2002. Function of the alternative oxidase: is it still a scavenger? Trends Plant Sci. 7:478-471.

Murphy, A. M., Chivasa, S., Singh, D. P., and Carr, J. P. 1999. Salicylic acid induced resistance to viruses and other pathogens: a parting of the ways? Trends Plant Sci. 4:155-160.

Murphy, A. M., Gilliland, A., York, C. J., Hyman, B., and Carr, J. P. 2004. High-level expression of alternative oxidase protein sequences enhances the spread of viral vectors in resistant and susceptible plants. J. Gen. Virol. 85:3777-3786.

Navarre, D. A. Wendehenne, D., Durner, J., Noad, R., and Klessig, D. F. 2000. Nitric oxide modulates the activity of tobacco aconitase. Plant Physiol. 122:573-582.

Navrot, N., Rouhier, N., Gelhaye, E., and Jacquot, J. P. 2007. Reactive oxygen species generation and antioxidant systems in plant mitochondria. Physiol. Plant. 129:185-195.

Naylor, M., Murphy, A. M., Berry, J. O., and Carr, J. P. 1998. Salicylic acid can induce resistance to plant virus movement. Mol. Plant-Microbe Interact. 11:860-868.

Noctor, G., Paepe, R. D., and Foyer, C. H. 2006 Mitochondrial redox biology and homeostasis in plants. Trends Plant Sci. 12:125-134.

Norman, C., Howell, K. A., Millar, A. H., Whelan, J. M., and Day, D. A. 2004. Salicylic acid is an uncoupler and inhibitor of mitochondrial electron transport. Plant Physiol. 134:492-501. 
Planchet, E., Gupta, K. J., Sonoda, M., and Kaiser, W. M. 2005. Nitric oxide emission from tobacco leaves and cell suspensions: rate limiting factors and evidence for the involvement of mitochondrial electron transport. Plant J. 41:732-743.

Purvis, A. C., and Shewfelt, R. L. 1993. Does the alternative pathway ameliorate chilling injury in sensitive plant tissues? Physiol. Plant. 88:712-718

Salgado, I., Modolo, L. V., Augusto, O., Braga, M. R., and Oliveira, H. C. 2006. Mitochondrial nitric oxide synthesis during plant-pathogen interactions: role of nitrate reductase in providing substrates. Plant Cell Monogr. 6:239-254.

Shi, K., Fu, L. J., Dong, D. K., Zhou, Y. H., and Yu, J. Q. 2008. Decreased root energy synthesis is partially compensated by a switch to sucrose synthase pathway of sucrose degradation in restricted root of tomato plants. Plant Physiol. Biochem. 46:1040-1044.

Shlizerman, L., Marsh, K., Blumwald, E., and Sadka, A. 2007. Iron-shortage-induced increase in citric acid content and reduction of cytosolic aconitase activity in Citrus fruit vesicles and calli. Physiol. Plant. 131:72-79.

Siedow, J. N., and Umbach, A. L. 1995. Plant mitochondrial electron transfer and molecular biology. Plant Cell 7:821-831.

Simons, B. H., Millenaar, F. F., Mulder, L., Van Loon, L. C., and Lambers, H. 1999. Enhanced expression and activation of the alternative oxidase during infection of Arabidopsis with Pseudomonas syringae pv. tomato. Plant Physiol. 120:529-538.

Singh, D. P., Moore, C. A., Gilliland, A., and Carr, J. P. 2004 Activation of multiple antiviral defence mechanisms by salicylic acid. Mol. Plant Pathol. 5:57-63.

Song, F. M., and Goodman, R. M. 2001. Activity of nitric oxide is dependent on, but is partially required for function of, salicylic acid in the signaling pathway in tobacco systemic acquired resistance. Mol. PlantMicrobe Interact. 14:1458-1462.

Suárez, M. H., Rodríguez, E. R., and Romero, C. D. 2008. Analysis of organic acid content in cultivars of tomato harvested in Tenerife. Eur. Food Res. Technol. 226:423-435

Szal, B., Jolivet, Y., Hasenfratz-Sauder, M.-P, Dizengremel, P., and Rychter, A. M. 2003. Oxygen concentration regulates alternative oxidase expression in barley roots during hypoxia and post-hypoxia. Physiol. Plant. 119:494-502.

Tada, Y., Spoel, S. H., Pajerowska-Mukhtar, K., Mou, Z., Song, J., Wang,
C., Zuo, J., and Dong, X. 2008. Plant immunity requires conformational changes of NPR1 via S-nitrosylation and thioredoxins. Science 321:952-956.

Tischner, R., Planchet, E., and Kaiser, W. M. 2004. Mitochondrial electron transport as a source for nitric oxide in the unicellular green alga Chlorella sorokiniana. FEBS (Fed. Eur. Biochem. Soc.) Lett. 576:151155.

Umbach, A. L., Fiorani, F., and Siedow, J. N. 2005. Characterization of transformed Arabidopsis with altered alternative oxidase levels and analysis of effects on reactive oxygen species in tissue. Plant Physiol. 139:1806-1820.

Vanlerberghe, G. C., and McIntosh, L. 1996. Signals regulating the expression of the nuclear gene encoding alternative oxidase of plant mitochondria. Plant Physiol. 111:589-595.

Vanlerberghe, G. C., and McIntosh, L. 1997. Alternative oxidase: from gene to function. Annu. Rev. Plant Physiol. Plant Mol. Biol. 48:703734.

Vidal, G., Ribas-Carbo, M., Garmier, M., Dubertret, G., Rasmusson, A. G., Mathieu, C., Foyer, C. H., and De Paepe, R. 2007. Lack of respiratory chain Complex I impairs alternative oxidase engagement and modulates redox signaling during elicitor-induced cell death in tobacco. Plant Cell 19:640-655.

Watanabe, C. K., Hachiya, T., Terashima, I., and Noguchi, K. 2008. The lack of alternative oxidase at low temperature leads to a disruption of the balance in carbon and nitrogen metabolism, and to an up-regulation of antioxidant defence systems in Arabidopsis thaliana leaves. Plant Cell Environ. 31:1190-1202.

Wong, C. E., Carson, R. A. J., and Carr, J. P. 2002. Chemically induced virus resistance in Arabidopsis thaliana is independent of pathogenesisrelated protein expression and the NPRI gene. Mol. Plant-Microbe Interact. 15:75-81.

Yamasaki, H., Shimoji, H., Ohshiro, Y., and Sakihama, Y. 2001. Inhibitory effects of nitric oxide on oxidative phosphorylation in plant mitochondria. Nitric Oxide 5:261-70.

Yoshida, K., Terashima, I., and Noguchi, K. 2007. Up-regulation of mitochondrial alternative oxidase concomitant with chloroplast over-reduction by excess light. Plant Cell Physiol. 48:606-614.

Zhou, B. Y., Guo, Z. F., Xing, J. P., and Huang, B. R. 2005. Nitric oxide is involved in abscisic acid-induced antioxidant activities in Stylosanthes guianensis. J. Exp. Bot. 56:3223-3228. 